\title{
Variable Energy X-ray Photoemission Studies of Alkylsilane Based Monolayers on Gold
}

\author{
Thomas M. Owens, ${ }^{\dagger}$ Sefik Siizer, ${ }^{*,+}$ and Mark M. Banaszak Holl ${ }^{*}, \dagger$ \\ Department of Chemistry, University of Michigan, Ann Arbor, Michigan 48109-1055, and \\ Chemistry Department, Bilkent University, 06533 Ankara, Turkey
}

Received: August 15, 2002; In Final Form: February 3, 2003

\begin{abstract}
Gaseous $n$-hexylsilane $\left(\mathrm{C}_{6} \mathrm{H}_{13} \mathrm{SiH}_{3}\right)$, $n$-octylsilane $\left(\mathrm{C}_{8} \mathrm{H}_{17} \mathrm{SiH}_{3}\right)$, and $n$-octadecylsilane $\left(\mathrm{C}_{18} \mathrm{H}_{37} \mathrm{SiH}_{3}\right)$ have been vapor deposited in ultrahigh vacuum (UHV) on freshly evaporated gold surfaces to form monolayers. Surface sensitive X-ray photoemission studies utilizing synchrotron radiation in the $160-360 \mathrm{eV}$ range have been used to characterize these systems. Analyses of the $\mathrm{C} 1 \mathrm{~s}, \mathrm{Si} 2 \mathrm{p}$, and $\mathrm{Au} 4 \mathrm{f}$ and valence band regions permit a structural assessment of the monolayer. The full width at half-maximum of the Si $2 \mathrm{p}$ and $\mathrm{C} 1 \mathrm{~s}$ core levels, 0.4 and 1.2 or $1.1 \mathrm{eV}$, respectively, suggest the monolayers are chemically homogeneous. The intensity variation of the $\mathrm{Au} 4 \mathrm{f}$ and $\mathrm{Si} 2 \mathrm{p}$ core levels at different photon energies indicate the surface coverage of the monolayer is $\sim 96 \%$ and the chain orientation is upright on the surface, not parallel to the surface. The valence band of the alkylsilane monolayers exhibit features at $\sim-13.2,-14.6,-16.3,-17.6$, and $-18.9 \mathrm{eV}$ that agree well with those observed for alkyl chains of the same length.
\end{abstract}

\section{Introduction}

The structure of thin films and monolayers on metal surfaces is critical to many industrial processes. ${ }^{1}$ Alkylsilanes $\left(\mathrm{H}_{2 n+1} \mathrm{C}_{n^{-}}\right.$ $\mathrm{SiH}_{3}$ ) have been shown to form monolayers on $\mathrm{Au}$ when deposited under UHV conditions at room temperature through $\mathrm{Si}-\mathrm{H}$ bond activation. ${ }^{2}$ However, the initial studies provided limited information regarding orientation of the alkyl chains. On the basis of recent literature precedent, two general structural models must be considered. Alkanes have been observed to lie flat on a gold surface and are believed to bind via physisorbtion. ${ }^{3}$ By way of contrast, $\mathrm{Me}_{3} \mathrm{Si}$-substituted alkanes are observed to stand upright and are proposed to have a pentacoordinate silicon atom and a covalent $\mathrm{Si}-\mathrm{Au}$ bond. ${ }^{4}$ The $\mathrm{H}_{3} \mathrm{Si}$-substituted alkanes utilized in this work fall in the middle of these two examples in terms of steric effects. However, as determined by X-ray photoelectron spectroscopy, the $\mathrm{H}_{3} \mathrm{Si}$ groups are quite reactive with the gold surface and it is proposed that all three $\mathrm{Si}-\mathrm{H}$ bonds are broken and replaced by $\mathrm{Si}-\mathrm{Au}$ bonds to give a tetrahedral $\mathrm{RSiAu}_{3}$ center.

In this paper, X-ray photoemission core level and valence band data are used to assess the structure of the $\mathrm{RSiH}_{3}$ derived monolayers and the degree of surface coverage. The full-width at half-maximum (fwhm) of the Si $2 p$ and $\mathrm{C} 1$ s core levels indicate that each of these atoms exists in a homogeneous environment in the monolayer. The valence band spectra of the monolayers are consistent with the alkyl chains remaining intact upon reaction of the $\mathrm{Si}$ atom with the $\mathrm{Au}$ surface. The attenuation of core level photoelectrons as a function of incident photon energy $(160-360 \mathrm{eV})$ has been used to determine the extent of surface coverage and the orientation of the alkyl chain with respect to the Au surface.

Spectroscopic techniques affording a high degree of surface sensitivity are necessary to investigate the structure and com-

\footnotetext{
* Corresponding authors. E-mail: suzer@fen.bilkent.edu.tr, mbanasza@ umich.edu.

$\dagger$ University of Michigan.

$\doteqdot$ Bilkent University.
}

position of thin films and monolayers. X-ray photoemission spectroscopy (XPS) with a conventional source probes the first $\sim 50 \AA$ of a material. Although this allows examination of the near surface region, information specific to the chemical environment of the atoms at the surface/vacuum interface may remain unobserved due to the intensity of the bulk features. Several methods have been developed to enhance the surface sensitivity of XPS, though almost all have a drawback. ${ }^{5,6}$ The surface sensitivity of XPS can be greatly improved by employing a synchrotron source. By employing a photon with an energy tens of electronvolts $(\mathrm{eV})$ above the threshold energy of the core level of interest, one can minimize the escape depth of the photoelectrons, resulting in a reduction in the signal from the bulk substrate. For example, in this work utilizing photon energies between 160 and $360 \mathrm{eV}$, we observed Si 2p core level photoelectrons emitting with kinetic energies between 60 and $260 \mathrm{eV}$. For the sake of comparison, when a conventional $\mathrm{Mg}$ $\mathrm{K} \alpha$ source is used, the emitted photoelectron has an energy of $\sim 1154 \mathrm{eV}$. This difference in emitted photon energy directly correlates to a $\sim 5-10 \AA$ as opposed to $\sim 50 \AA$ sampling depth, respectively. In addition, photoelectron cross-sections are energy dependent and desired core levels can be maximized through the proper selection of photon energy. ${ }^{7}$ This is useful when attempting to study the valence band region or a core level with a small photoelectron cross section when typical X-ray sources are used.

\section{Experimental Section}

$n$-Hexylsilane $\left(\mathrm{H}_{13} \mathrm{C}_{6} \mathrm{SiH}_{3}\right), n$-octylsilane $\left(\mathrm{H}_{17} \mathrm{C}_{8} \mathrm{SiH}_{3}\right)$, and $n$-octadecylsilane $\left(\mathrm{H}_{37} \mathrm{C}_{18} \mathrm{SiH}_{3}\right)$ were purchased from Gelest, Inc. (Morrisville, PA), loaded into UHV compatible tubes and underwent multiple freeze-pump-thaw cycles prior to use. ${ }^{8}$

Samples consisted of $\mathrm{Si}$ wafers onto which a thin $\mathrm{Cr}$ layer was evaporated, followed by $\sim 1500 \AA$ of $\mathrm{Au}$. A fresh Au layer was evaporated in vacuo prior to exposure. Sample cleanliness was assessed by XPS. Dosing was accomplished by backfilling a chamber with the desired alkylsilane using a variable sapphire leak valve. Evaporation of $\mathrm{Au}$ and alkylsilane exposures were 

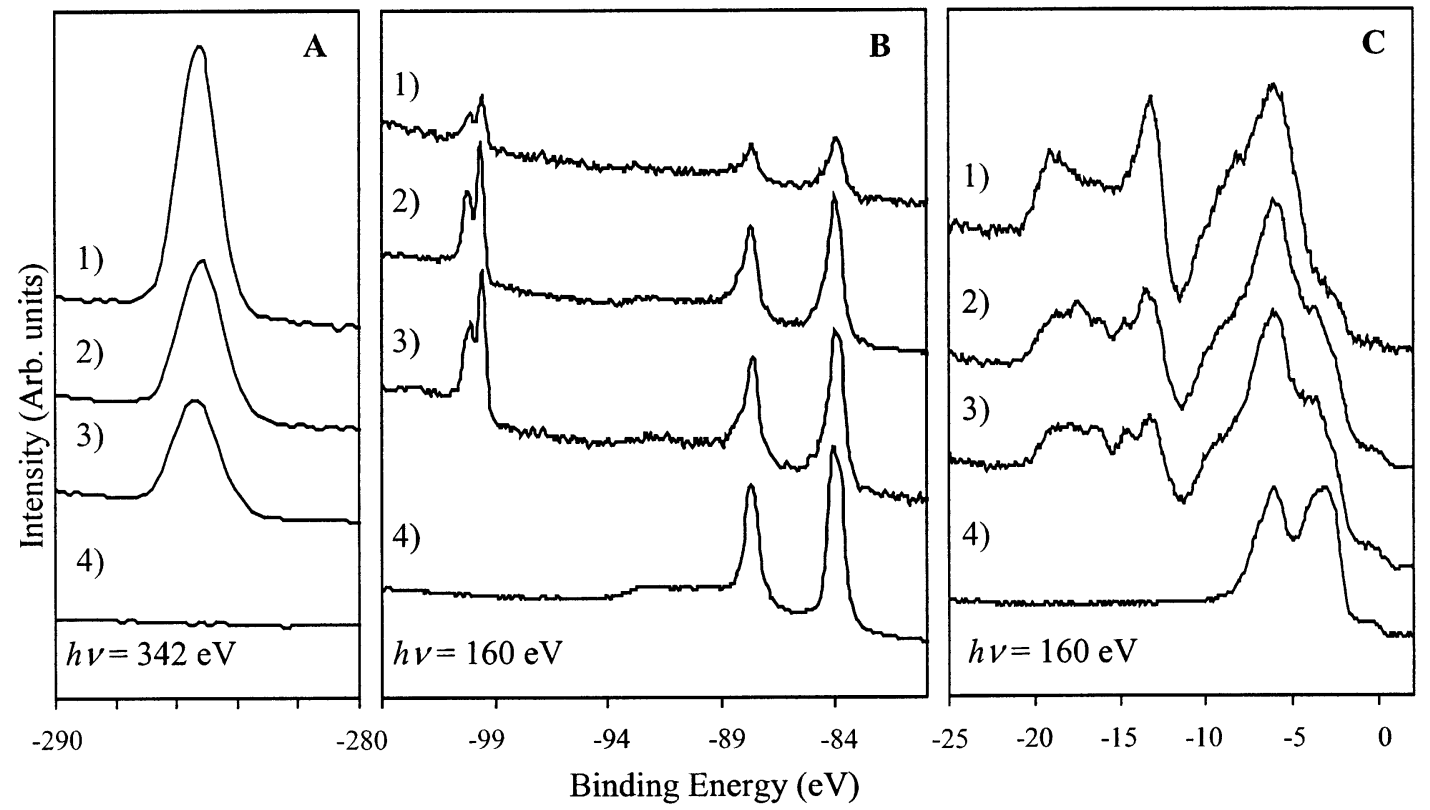

Figure 1. (A) $\mathrm{C} 1 \mathrm{~s}$ core level, (B) Si 2p and $\mathrm{Au} 4 \mathrm{f}$ core levels, and (C) valence band region for (1) octadecylsilane, (2) octylsilane, and (3) hexylsilane monolayers on (4) Au. The binding energy has been referenced to $\mathrm{Au} 4 \mathrm{f}_{7 / 2}=-84.0 \mathrm{eV}$. The decrease in the intensity of the Au $4 \mathrm{f}$ and Si $2 p$ core levels observed in B (1-3) can be accounted for by the attenuation of the photoelectrons through the hydrocarbon overlayer.

performed in separate chambers. All reactions were performed at room temperature $\left(\sim 20^{\circ} \mathrm{C}\right)$.

XPS was performed at beamline U8B at the National Synchrotron Light Source using monochromatic light. The beamline and endstation have been previously described. ${ }^{9}$ Evaporation of $\mathrm{Au}$ and dosing were performed in separate chambers isolated by gate valves. Photon energies between 160 and $360 \mathrm{eV}$ were employed. Spectra were referenced to the binding energy of the $\mathrm{Au} 4 \mathrm{f}_{7 / 2}$ core level at $-84.0 \mathrm{eV}$. The position of the sample was not altered between the collection of spectra at various photon energies. The instrumental resolution is estimated to be $<0.20 \mathrm{eV} .^{10}$ The precision of the corelevel fits, and therefore of the binding energies reported, is $<0.05 \mathrm{eV}$. Note that we are using two different incident photon energies to obtain the $\mathrm{Si} 2 \mathrm{p}$ and $\mathrm{C}$ 1s core level data (160 and $342 \mathrm{eV}$, respectively). The difference in the fwhm of the incident photons at these energies, coupled with the fact that $\mathrm{Si} 2 \mathrm{p}$ and $\mathrm{C}$ 1s have differing natural line widths, prevents the magnitude of the fwhm values for $\mathrm{Si} 2 \mathrm{p}$ and $\mathrm{C} 1$ s from being meaningfully compared to one another.

\section{Results and Discussion}

Photoemission data can be utilized to extract useful physicochemical information on the overlayer and the substrate. The binding energies of the core levels can be used to determine the chemical composition of the monolayer. In addition, the fwhm of the core levels is sensitive to the chemical environment. When data are acquired on a core level at various incident photon energies, depth profiling based on the attenuation length of the photoelectron can be performed. This allows conclusions to be drawn regarding the orientation of the alkyl chains in the overlayer.

Chemical Composition and Structure. The Si $2 p$ core level $(h v=160 \mathrm{eV})$ consists of a spin-orbit doublet (for hexylsilane Si $2 p_{3 / 2}=-99.7 \mathrm{eV}$, for octyl- and octadecylsilane Si $2 \mathrm{p}_{3 / 2}=$ $-99.8 \mathrm{eV})$, as does the $\mathrm{Au} 4 \mathrm{f}$ core level $\left(\mathrm{Au} \mathrm{4f_{7/2 }}=-84.0 \mathrm{eV}\right)$ (Figure 1B). ${ }^{11}$ In each case, the $\mathrm{C} 1 \mathrm{~s}$ core level $(h v=342 \mathrm{eV})$ is apparent as a single feature at $\sim-285 \mathrm{eV}$ (Figure 1A). The valence band region $(h v=160 \mathrm{eV})$ is dominated by features

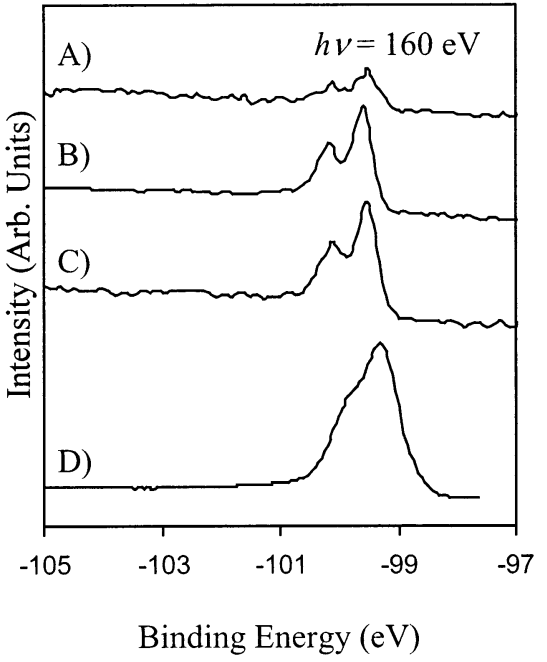

Figure 2. Si $2 p$ core level for (A) octadecylsilane, (B) octylsilane, and (C) hexylsilane on Au. (D) Si $2 p$ core level for clean Si(100)$2 \times 1$. The Si atoms of the alkylsilane monolayers are in a homogeneous chemical environment, as indicated by the narrow fwhm of $0.4 \mathrm{eV}$ and the dramatic spin-orbit splitting as compared to the clean $\mathrm{Si}(100)$ $2 \times 1$ surface.

arising from the $\mathrm{C} 2 \mathrm{~s}$ and $2 \mathrm{p}$ orbitals of the alkyl chain $(-10-$ $20 \mathrm{eV}$ ) as well as the $\mathrm{Au} 5 \mathrm{~d}$ electrons $(\sim-3-6 \mathrm{eV})$ (Figure 1C). The feature ascribed to the $\mathrm{Au} 6 \mathrm{~s}$ at $\sim 0 \mathrm{eV}$ is visible even after reaction with the alkylsilane (seen more clearly in Figure 4). On the basis of the lack of change in the appearance of this feature after reaction, we propose the $\mathrm{Au} 6 \mathrm{~s}$ orbital is not involved in the $\mathrm{Si}-\mathrm{Au}$ bonds. As surface gold hydrides are not stable at room temperature, ${ }^{12}$ the most likely fate of the hydrogen is reductive elimination as $\mathrm{H}_{2}$. Key data related to the alkylsilanes are summarized in Table 1. As these are the features that will be used to examine the formation of the monolayer on the surface and determine the thickness, a more thorough discussion of the nuances of the spectral regions is warranted.

As seen in Figure 2, the splitting arising from spin-orbit coupling is readily apparent in the Si $2 p$ core level data obtained with a photon energy of $160 \mathrm{eV}$. The $\mathrm{Si} 2 \mathrm{p}_{3 / 2}$ feature is at 
TABLE 1: Selected Curve Fitting Parameters for the Alkylsilane Monolayers on Au

\begin{tabular}{llll}
\hline & $\mathrm{H}_{13} \mathrm{C}_{6} \mathrm{SiH}_{3}$ & $\mathrm{H}_{17} \mathrm{C}_{8} \mathrm{SiH}_{3}$ & $\mathrm{H}_{37} \mathrm{C}_{18} \mathrm{SiH}_{3}$ \\
\hline $\mathrm{Si}$ 2p $\mathrm{p}_{3 / 2} \mathrm{BE}(\mathrm{eV})$ & -99.7 & -99.8 & -99.8 \\
$\mathrm{Si} 2 \mathrm{p}$ fwhm & 0.4 & 0.4 & 0.4 \\
$\mathrm{C}$ 1s BE $(\mathrm{eV})$ & -284.7 & -284.9 & -285.0 \\
$\mathrm{C}$ 1s fwhm & 1.2 & 1.2 & 1.1 \\
$\mathrm{C}$ 1s area & 6 & 8 & 12
\end{tabular}

$\sim-99.7 \mathrm{eV}$ for the hexylsilane monolayer and $\sim-99.8 \mathrm{eV}$ for the octyl- and octadecylsilane monolayers. The observed full width at half-maximum (fwhm) for each of the silane-based monolayer Si $2 p$ core levels is $0.4 \mathrm{eV}$. This is $\sim 0.1 \mathrm{eV}$ narrower than the typical fwhm observed for bulk, crystalline Si using the same beamline and monochromator. To evaluate the implications of the fwhm for the alkylsilane monolayers, both initial state ${ }^{13}$ and final state ${ }^{14}$ effects must be considered. For comparison, the Si 2 p core level of a clean Si (100)- $2 \times 1$ sample is included (Figure 2D). The spin-orbit splitting for crystalline $\mathrm{Si}(100)-2 \times 1$ is not as well resolved due to the presence of $\mathrm{Si}$ atoms in different chemical environments (initial state effect) near the surface. ${ }^{15} \mathrm{Si}$ atoms at the surface have slightly different binding energies (the asymmetry observed to the low binding energy side of Figure 2D) than the bulk atoms. These shifts are to both higher and lower binding energy. In addition to considerations of local geometry (initial states), inclusion of final state effects is critical to the accurate calculation of the direction and magnitudes of the binding energy shifts of these features with respect to the bulk Si peak. ${ }^{16}$ The sum of the initial and final state effects results in the binding energy of the $\mathrm{Si} 2 \mathrm{p}_{1 / 2}$ core level for the surface states to be between the peaks of the bulk $\mathrm{Si}$ atoms. Thus, the surface states obscure the observation of two distinct features on the $\operatorname{Si}(100)-2 \times 1$ surface. Features with binding energy shifts less than the experimental resolution are unresolved and contribute to an increase in the fwhm of the core level.

The narrow fwhm observed for the alkylsilane-based monolayers is an indication of the homogeneity of the chemical environment of the $\mathrm{Si}$ on the $\mathrm{Au}$ surface (initial state). If multiple bonding environments were present, the fwhm for the $\mathrm{Si} 2 \mathrm{p}$ core level would be wider, as observed for $\operatorname{Si}(100)-2 \times 1$. The narrow fwhm and the absence of two or more discrete Si $2 p$ features also indicate that multilayers have not formed. If multilayers had formed, $\mathrm{Si}$ atoms in the overlayers would not be bonded to the $\mathrm{Au}$ surface and, in addition to being in a different chemical (initial state) environment, would also be in a different physical (final state) environment than those Si atoms bonded to the Au surface. On the basis of an estimated $\sim 11 \AA$ layer thickness, final state perturbations to the binding energy are predicted to exceed $1 \mathrm{eV}$ in magnitude. ${ }^{17} \mathrm{~A}$ binding energy shift of this magnitude would result in the presence of another peak in the Si 2 p spectrum as this shift is far greater than the $0.4 \mathrm{eV}$ fwhm observed for the $\mathrm{Si}$ atoms in the monolayer.

Also noteworthy is the binding energy of the $\mathrm{Si} 2 \mathrm{p}$ core level for the silane-based monolayers in comparison to that of the clean Si surface. The Si $2 p$ core level of the monolayers has a binding energy that is similar to the clean Si surface $(-99.3$ $\mathrm{eV}$ ). This suggests the reaction between the silane and the $\mathrm{Au}$ surface occurs through the activation of all three of the $\mathrm{Si}-\mathrm{H}$ bonds. Silicon hydrides on surfaces are known to exhibit a binding energy shift of between 0.3 and $1 \mathrm{eV}$ to higher binding energy. ${ }^{18}$ Recent photoemission studies of alkanes chemisorbed to $\mathrm{Si}(111)$ report a binding energy shift of $0.2-0.3 \mathrm{eV}$ to higher binding energy for the $\mathrm{Si}$ atoms bonded to the carbon atom. ${ }^{19}$

The decrease in the intensity of the $\mathrm{Si} 2 \mathrm{p}$ and $\mathrm{Au} 4 \mathrm{f}$ core levels with increasing alkyl chain length (Figures 2 and 3D-

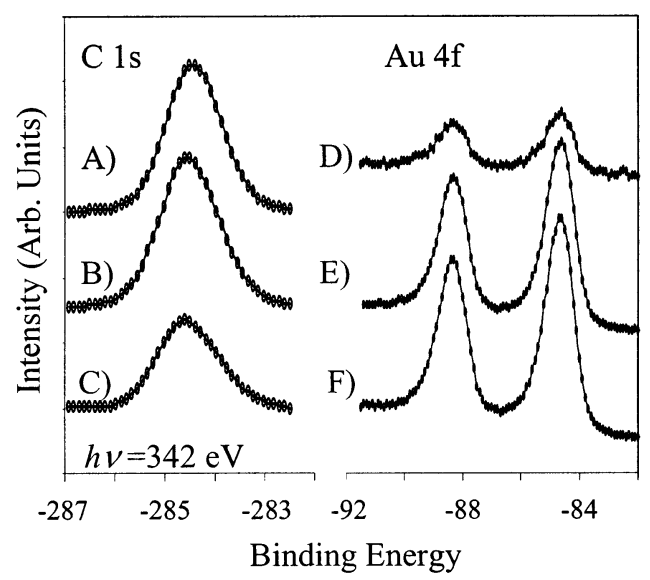

Figure 3. $\mathrm{C} 1 \mathrm{~s}$ and $\mathrm{Au} 4 \mathrm{f}$ core levels for octadecylsilane (A and $\mathrm{D}$, respectively), octylsilane (B and $\mathrm{E}$ ) and hexylsilane ( $\mathrm{C}$ and $\mathrm{F}$ ) on $\mathrm{Au}$. The fwhm of the $\mathrm{C} 1 \mathrm{~s}$ core level decreases from $1.2 \mathrm{eV}$ for the hexylsilane to $1.1 \mathrm{eV}$ for the octadecylsilane. As the intensity of the $\mathrm{C}$ $1 \mathrm{~s}$ core level increases with longer alkyl chain, the intensity of the Au 4f core level diminishes.

F) is critical to the assessment of the gross bonding geometry of the alkylsilane on the Au surface. The Au 4f and Si 2p core levels are diminished to the same degree in each of the spectra presented, whereas the intensity of the $\mathrm{C} 1$ s core level increases with increasing chain length. This indicates that the $\mathrm{Au}$ and $\mathrm{Si}$ photoelectrons must traverse a thicker overlayer to escape the surface. The ratio of the integrated peak area for the $\mathrm{C} 1 \mathrm{~s}$ core level for the alkylsilane monolayers is 6:8:12 for hexylsilane to octylsilane to octadecylsilane. ${ }^{20}$ The lower than expected value for the octadecylsilane is consistent with the attenuation of the $\mathrm{C} 1$ s photoelectrons from near the $\mathrm{Si} / \mathrm{Au}$ interface. ${ }^{21}$ The electrons ejected from these buried $\mathrm{C}$ atoms must traverse an overlayer of approximately the same thickness as those arising from the $\mathrm{Si}$ and $\mathrm{Au}$ atoms. This attenuation of the photoelectrons will be examined in detail later in this paper.

As enumerated in Table 1, the fwhm of the $\mathrm{C} 1$ s core level decreases by $0.1 \mathrm{eV}$ as the length of the alkyl chain increases from eight carbon atoms to eighteen. Several factors likely contribute to this narrowing. The most rudimentary explanation is more of the carbon atoms of the alkyl chain are in a chemically homogeneous environment. A similar argument can be made for the chains being ordered in the monolayer. If the alkyl chains are ordered, a more homogeneous chemical environment exists for the $\mathrm{C}$ atoms. Another factor that can influence the apparent homogeneity of the feature is the degree to which the photoelectrons emitted from $\mathrm{Si}-\mathrm{CH}_{2}$ are attenuated by the overlayer. The methylene group has a unique local chemical environment that could result in a binding energy shift that would increase the fwhm of the $\mathrm{C} 1 \mathrm{~s}$ core level. ${ }^{22}$ As the length of the alkyl chain increases, the attenuation of the photoelectrons from the Si-bound methylene will also increase. ${ }^{19}$ Least-squares curve fitting of the $\mathrm{C} 1 \mathrm{~s}$ data gives reasonable fits when a single function is fit to the data. Each of the spectra, however, exhibit an asymmetry toward the low binding energy side of the $\mathrm{C} 1 \mathrm{~s}$ feature.

The valence band spectra of the dosed samples are distinguished by the appearance of features between $\sim-10-20 \mathrm{eV}$ and the dramatic change in the appearance of the peaks at $\sim-3-6 \mathrm{eV}$. These low binding energy features are most readily assigned as a convolution of the $\mathrm{C} 2 \mathrm{p}$ and the Au 5d levels. No discernible feature has been correlated to either the $\mathrm{Si} 3 \mathrm{~s}$ or the Si $3 p$ orbital; however, they should also be manifest in the -1 to $-4 \mathrm{eV}$ region. The feature between -12 and $-20 \mathrm{eV}$ arises 


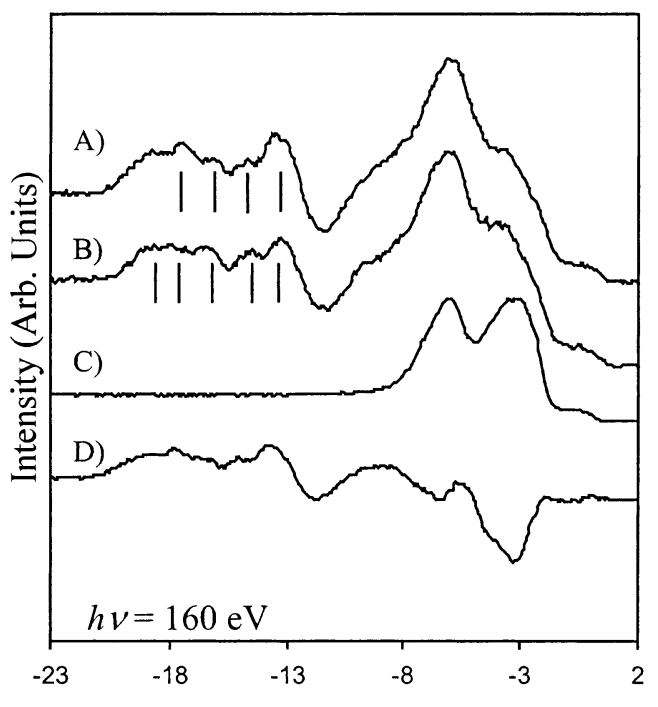

Binding Energy (eV)

Figure 4. Valence band region for (A) octylsilane on $\mathrm{Au}$, (B) hexylsilane on $\mathrm{Au}$, and (C) freshly evaporated Au. (D) Difference spectrum of octylsilane monolayer valence band (A) after subtraction of clean gold spectrum (C). C 2 s features observed for solid-phase hexane and octane are indicated (from ref 23) in the spectra of the hexylsilane and octylsilane monolayers, respectively. These features are still observed after subtraction (D). The negative feature in spectrum $\mathrm{D}$ results from a change in the electronic structure of the Au $5 \mathrm{~d}$ electrons after reaction with the silane.

TABLE 2: Observed Peaks in the Valence Band Assigned to C 2s Photoelectrons (Energy Values in $\mathrm{eV}$ )

\begin{tabular}{ccc}
\hline hexylsilane & octylsilane & octadecylsilane \\
\hline-13.2 & -13.4 & -13.1 \\
-14.5 & -14.7 & -19.2 \\
-16.4 & -16.2 & \\
-18.0 & -17.4 & \\
-18.9 & -18.7 &
\end{tabular}

from the $\mathrm{C} 2 \mathrm{~s}$ orbitals of the alkyl chains (Table 2). Comparing the $C 2 \mathrm{~s}$ feature to that of straight chain alkanes of the same length is informative. Four features are observed for octane in the $\mathrm{C} 2 \mathrm{~s}$ region of the valence band spectra, whereas five are observed for hexane. ${ }^{23}$ The binding energy at which the features are observed for each of the respective alkanes is indicated in Figure 4 (vertical lines) with respect to the valence band for the alkylsilane monolayers. As demonstrated by the data in Figure 4, there is a high degree of correlation between the peaks observed in the spectra of the solid alkane and those of the alkylsilane monolayers. As the structure of the $\mathrm{C} 2$ s feature is dependent on the number of $\mathrm{C}$ atoms present in the chain, the observed similarity between the solid alkanes and the alkylsilane monolayers indicates the carbon chain remains intact when the monolayer is formed. This is in good agreement with previous data from reflection-adsorption infrared spectroscopy studies. ${ }^{2}$

It is also evident from the valence band that the reaction between the alkylsilanes and the $\mathrm{Au}$ surface involves the $\mathrm{Au}$ $5 \mathrm{~d}$ electrons. Though the Au 5d feature is convoluted by overlap with the Si $3 p$ and C $2 p$ orbitals, subtraction of the clean Au spectrum results in a difference spectrum (Figure 4D for octylsilane on $\mathrm{Au}$ ) that does not reproduce that of the alkylsilane. ${ }^{24} \mathrm{~A}$ negative feature is observed in the difference spectra correlating to the $\mathrm{Au} 5 \mathrm{~d}_{5 / 2}$ peak. A similar negative feature for the $\mathrm{Au} 5 \mathrm{~d}_{3 / 2}$ peak is expected, though not observed. This is likely due to overlap with the photoelectrons emitted from the $\mathrm{C} 2 \mathrm{p}$ and $\mathrm{Si} 3 \mathrm{~s}$ and $3 \mathrm{p}$ orbitals. As the photoelectron cross sections of these orbitals is not known at $160 \mathrm{eV}$, an accurate deconvolution of the spectrum into the constituent peaks cannot be performed. No change is observed for the Au 6 s electrons $(\sim 0$ $\mathrm{eV})$, suggesting the $\mathrm{Au}-\mathrm{Si}$ bonds in the monolayers do not involve the Au 6s electrons.

Photoelectron Attenuation. Bouguer-Lambert's law of exponential attenuation for an electron beam traversing an overlayer together with known attenuation lengths of electrons have been successfully applied to experimental data to extract thickness information in the $1-10 \mathrm{~nm}$ range using photoelectron and/or Auger peaks. ${ }^{25,26}$ Bain and Whitesides measured the attenuation length of the photoelectrons in the 900-1400 eV range using self-assembled monolayers of alkanethiols on gold ${ }^{21}$ by means of XPS, and Laibinis, Bain, and Whitesides extended these measurements to similar monolayers on copper and silver. ${ }^{27}$ Beard and Brizzolara reported similar measurements and discussed the possible sources of errors and methods to correct them. ${ }^{28}$ A recent study by Lamont and Wilkes extended the measurement of the attenuation length of electrons down to $50 \mathrm{eV}$ by utilizing synchrotron radiation, ${ }^{29}$ whereas Kappen et al. developed a model for correcting for surface roughness and tested it on various purposely roughened model surfaces. ${ }^{6}$ The variability of the photoelectron attenuation length can be used to determine whether an adsorbate has formed a monolayer on a surface. ${ }^{30}$ A number of methods have been proposed to model the attenuation of the photoelectrons through solids ${ }^{31}$ and through an overlayer. ${ }^{29,32}$

The intensity of photoelectrons is exponentially attenuated by an overlayer of thickness, $d$, according to

$$
I(A)=I\left(A_{0}\right) \mathrm{e}^{-d / \lambda}
$$

where $\lambda$ is the attenuation length of the electrons traversing the overlayer, assuming a uniform overlayer thickness. ${ }^{25}$ For hydrocarbons, $\lambda$ varies between 5 and $25 \AA$ in the energy range of $50-1000 \mathrm{eV}$ and follows the so-called "universal curve" 33 with a minimum around $100 \mathrm{eV}^{25,29}$ If one assumes the monolayer thickness to be similar to alkanethiols, ${ }^{34}$ values of $d$ $=\sim 11$ and $\sim 22 \AA$ can be employed for the monolayers of octylsilane and octadecylsilane on gold and $d=\sim 9$ and $\sim 20$ $\AA$ for the monolayers of octane and octadecane on silicon, respectively. ${ }^{21}$ Tabulated values for experimentally measured attenuation lengths employing alkanethiols on gold were utilized. ${ }^{29}$ The overall shape of this curve, particularly the minimum at $\sim 100 \mathrm{eV}$, results from the photon energy dependence of the electron attenuation length. This dependence is related to inelastic electron scattering processes occurring as the photoelectron traverses the overlayer. ${ }^{35}$

In Figure 5A, the measured $\mathrm{Au} 4 \mathrm{f}$ intensity normalized to metallic gold is directly compared to the calculated $\mathrm{Au} 4 \mathrm{f}$ intensity as a function of the kinetic energy of the photoelectrons in the 50-260 eV range (photon energy of 160-360 eV). Over this range, the electron attenuation length through a hydrocarbon overlayer increases by a factor of 2 , from 6 to $12 \AA{ }^{6}$ Similar calculations for the $\mathrm{Si} 2 \mathrm{p}$ intensity together with the measured values are given in Figure 5B. Although the experimental data do not coincide with any of the calculated curves, it does fall within an appropriate range and possesses the general shape of the "universal" curve. Plots such as these are inherently limited by the assumptions in the formulation of the model system. The calculations are performed assuming an ideally flat surface and a perfect crystalline hydrocarbon overlayer. As the experimental data were obtained for a sample prepared on an evaporated $\mathrm{Au}$ surface, the differences in the experimental and computed curves are remarkably small. Although a precise value for the distance 


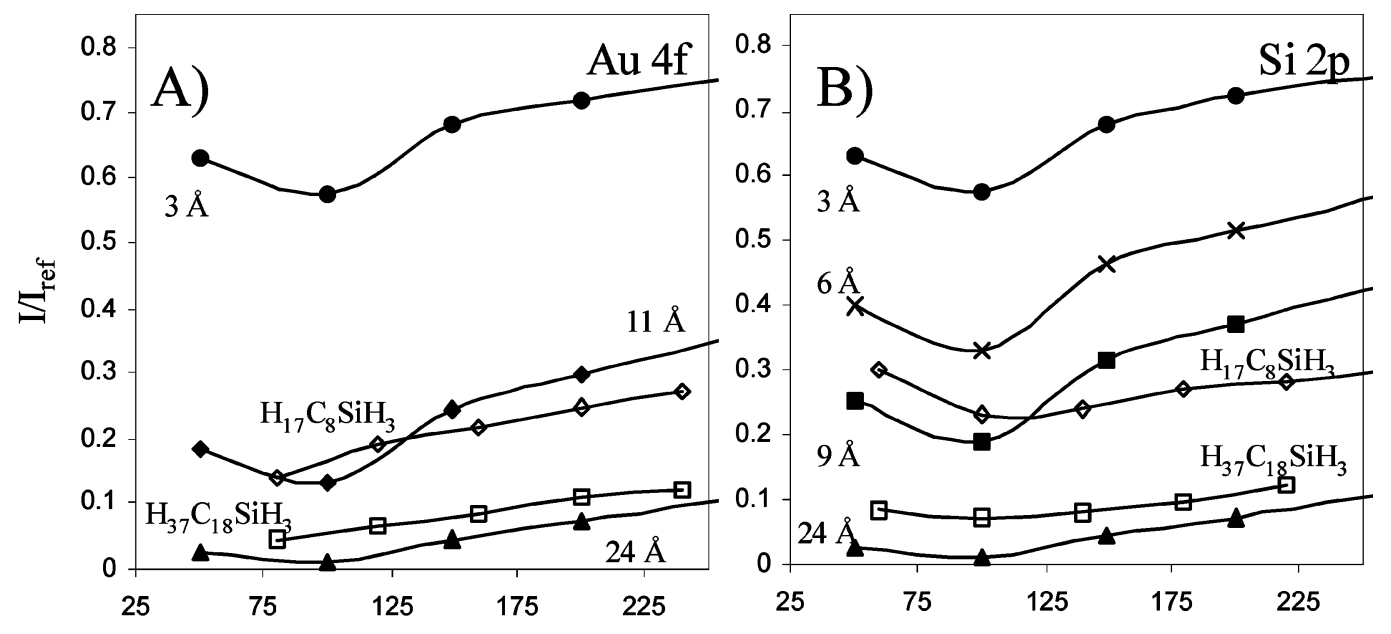

Kinetic Energy (eV)

Figure 5. Plots of normalized photoemission intensity versus electron kinetic energy for the (A) $A u 4 f_{7 / 2}$ and (B) Si $2 p_{3 / 2}$ core levels of octylsilane $(\diamond)$ and octadecylsilane $(\square)$. Data are normalized to clean $\mathrm{Au}$ and $\mathrm{Si}(100)$, respectively. Also plotted are the calculated normalized intensities for photoemission from a surface with a hydrocarbon overlayer of thickness $3(\boldsymbol{\bullet}), 6(\times), 9(\mathbf{\square}), 11(\bullet)$, and $24 \AA(\mathbf{\Delta})$. The experimental data for octylsilane agree reasonably well with the 9 and $11 \AA$ cases. Photon energies of 160, 200, 240, 280, 320, and $360 \mathrm{eV}$ were employed.

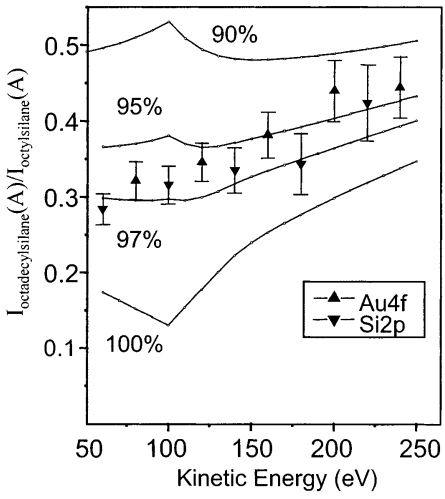

Figure 6. Experimental monolayer coverage based on photoelectron kinetic energy. Also plotted (from eq 4) are calculated intensity values for single phase surface coverages of $90,95,97$, and $100 \%$. The Si $2 p$ $(\boldsymbol{\nabla})$ and $\mathrm{Au} 4 \mathrm{f}(\boldsymbol{\Delta})$ experimental data are indicative of $\sim 96 \%$ surface coverage.

that photoelectrons traveled through the hydrocarbon overlayer cannot be determined for the alkylsilane monolayers, the data can be used to assess the degree of surface coverage.

In the case of the octylsilane, the degree of attenuation of both the Au and Si photoelectrons indicates there is $\sim 10 \AA$ of hydrocarbon that must be traversed (Figure 5). This agrees well with the length of octylsilane when the alkyl chain is fully extended $(\sim 11.6 \AA)$. The octadecylsilane data also exhibit a general agreement with the plot of a $24 \AA$ thick hydrocarbon overlayer, though very small attenuation differences are predicted for overlayers greater than $\sim 20 \AA$ in the range of photoelectron kinetic energy employed. Also evident from Figure 5, the data do not agree with the predicted intensity for a $\sim 3 \AA$ thick overlayer. As the possibility of multilayer formation has been effectively ruled out by the fwhm of the Si $2 \mathrm{p}$ and $\mathrm{C} 1 \mathrm{~s}$ core levels, the difference between the experimental data and the $\sim 3 \AA$ calculated curve eliminates the possibility that the alkylsilane molecules are oriented nearly parallel to the surface. ${ }^{36}$

Photoemission measurements using synchrotron radiation are more difficult to quantify than conventional source experiments due to various parameters such as beam stability, energy dependence of the atomic photoelectron cross section, charac- teristics of the monochromator, and the variation in photon flux, although the experimentally determined intensity ratios can be corrected for many of them. On the other hand, the ratio of the normalized intensities is more reliable as the above-mentioned experimental factors cancel out. Hence the variation in the ratio of the $\mathrm{Au} 4 \mathrm{f}$ intensity of octadecylsilane to that of octylsilane as a function of electron kinetic energy is an inherently more reliable experimental parameter to compare with the model. Accordingly, for $\mathrm{Au} 4 \mathrm{f}$ and $\mathrm{Si} 2 \mathrm{p}$ these ratios become identical ${ }^{37}$ and of similar shape to the intensity variation itself:

$$
\begin{aligned}
& \frac{I_{\text {octadecylsilane,Au4f }}(A)}{I_{\text {octylsilane,Au4f }}(A)}=\frac{I_{\text {octadecylsilane,Au4f }}\left(A_{0}\right) \mathrm{e}^{-22 \AA / \lambda}}{I_{\text {ocytlsilane,Au4f }}\left(A_{0}\right) \mathrm{e}^{-11 \AA / \lambda}}=\mathrm{e}^{-11 \AA / \lambda} \\
& \frac{I_{\text {octadecylsilane,Si2p }}(A)}{I_{\text {octylsilane,Si2p }}(A)}=\frac{I_{\text {octadecylsilane, } \mathrm{Si} 2 \mathrm{p}}\left(A_{0}\right) \mathrm{e}^{-20 \AA / \lambda}}{I_{\text {octylsilane, } \mathrm{Si} 2 \mathrm{p}}\left(A_{0}\right) \mathrm{e}^{-9 \AA / \lambda}}=\mathrm{e}^{-11 \AA / \lambda}
\end{aligned}
$$

Another point to consider is the partial coverage of the substrate (gold) surface, which can also be modeled:

$$
I(A)=\alpha I\left(A_{0}\right) \mathrm{e}^{-d / \lambda}+(1-\alpha) I\left(A_{0}\right)
$$

where $\alpha$ is the fraction of the surface covered. According to this model, the ratio of the normalized intensities

$$
\frac{I(A)}{I(A)^{\prime}}=\frac{\alpha I\left(A_{0}\right) \mathrm{e}^{-d / \lambda}+(1-\alpha) I\left(A_{0}\right)}{\alpha^{\prime} I\left(A_{0}\right)^{\prime} \mathrm{e}^{-d^{\prime} / \lambda}+\left(1-\alpha^{\prime}\right) I\left(A_{0}\right)^{\prime}}
$$

is a very sensitive function of coverage. Even when $\alpha=\alpha^{\prime}=$ 0.9 , the coverage deviates strongly from $\alpha=\alpha^{\prime}=1$, as shown in Figure 6, which shows 90, 95, 97, and 100\% coverage (lines) together with the experimental values (filled symbols) obtained for the $\mathrm{Si} 2 \mathrm{p}$ and $\mathrm{Au} 4 \mathrm{f}$ core levels. Calculated values of $I(A) /$ $I(A)^{\prime}$ with either $\alpha$ or $\alpha^{\prime}<0.85$ or disparate values of $\alpha$ and $\alpha^{\prime}$ do not reproduce the experimental data as well as $\alpha=\alpha^{\prime}=$ 0.9. By comparison of the experimental data with the theoretical curves generated using eq 4 , it is estimated that $\sim 95-97 \%$ of the Au surface is covered by the alkylsilane monolayers. 


\section{Conclusions}

The orientation and coverage of alkylsilane monolayers of various chain lengths on Au has been studied using synchrotron radiation. On the basis of the narrow fwhm $(0.4 \mathrm{eV})$ of the $\mathrm{Si}$ $2 p$ core level, the $\mathrm{Si}$ atoms in the monolayers are in a chemically homogeneous environment. The binding energy of the Si $2 p$ core level ( $\mathrm{Si} 2 \mathrm{p}_{3 / 2}=\sim-99.8 \mathrm{eV}$ ) is slightly larger than that observed for crystalline Si. This binding energy suggests that no $\mathrm{Si}-\mathrm{H}$ bonds remain in the monolayer. The $\mathrm{Si} 2 \mathrm{p}$ binding energy and fwhm support a bonding geometry in which Si has formed three bonds to the $\mathrm{Au}$ surface. The possibility of multilayer formation can be excluded on the basis of the homogeneity of the Si chemical environment required by the narrow Si $2 p$ core level fwhm. The attenuation of the emitted photoelectrons from the $\mathrm{Si} 2 \mathrm{p}$ and $\mathrm{Au} 4 \mathrm{f}$ core levels indicates that the electrons must traverse an overlayer to reach the detector. The $\mathrm{C} 1 \mathrm{~s}$ core level data are in agreement with this proposed bonding geometry. For octadecylsilane, the longest alkylsilane employed in this work, attenuation of the electrons emitted from the $\mathrm{C}$ atoms near the $\mathrm{Si}$ atom is observed. The valence band spectra of the alkylsilane monolayers exhibit a high correlation with those of solid, straight chain alkanes possessing the same number of carbon atoms. This is evidence that the alkyl chain remains intact upon formation of the monolayer and corroborates previous surface IR data. The intensity of the $\mathrm{Si}$ and $\mathrm{Au}$ core levels obtained at various incident photon energies agree qualitatively with the "universal" attenuation curve. On the basis of the degree of attenuation of the $\mathrm{Si}$ $2 \mathrm{p}$ and $\mathrm{Au} 4 \mathrm{f}$ photoelectrons, the alkyl chains are oriented at an angle with respect to the Au surface. Comparison of the experimentally obtained ratio to the calculated ratio for the surface coverage indicates $\sim 95-97 \%$ of the $\mathrm{Au}$ is covered by a hydrocarbon overlayer.

Acknowledgment. Dow Corning and the NSF (DMR0093641 and INT-0096583) are thanked for their support. Research was carried out at the National Synchrotron Light Source, Brookhaven National Laboratory, which is supported by the U.S. Department of Energy (Division of Materials Science and Division of Chemical Sciences of the Office of Basic Energy Sciences) under Contract No. DE-AC0298CH10886. M.M.B.H. appreciates the support of an Alfred P. Sloan Research Fellowship. S.S. is grateful for the support of a FulbrightFellowship. Dr. K. A. Miller is gratefully acknowledged for assistance in sample preparation. J. Kulman is thanked for the initial evaporation of the Au onto the Si. We thank Drs. K. Z. Zhang and K. T. Nicholson for assistance at U8B. We are grateful for enlightening discussions with K. S. Schneider and Dr. B. G. Orr.

\section{References and Notes}

(1) (a) Somorjai, G. A. Surface Chemistry and Catalysis; WileyInterscience: New York, 1994. (b) Lee, W. W.; Ho, P. S. Mater. Res. Soc. Bull. 1997, 22, 19.

(2) Owens, T. M.; Nicholson, K. T.; Banaszak Holl, M. M.; Süzer, S. J. Am. Chem. Soc. 2002, 124, 6800.

(3) (a) Marchenko, O.; Cousty, J. Phys. Rev. Lett. 2000, 84, 5363. (b) Uosaki, K.; Yamada, R. J. Am. Chem. Soc. 1999, 121, 4090.

(4) Marchenko, A.; Katsonis, N.; Fichou, D.; Aubert, C.; Malacria, M. J. Am. Chem. Soc. 2002, 124, 9998.

(5) (a) Dalmia, A.; Liu, C. C.; Savinell, R. F. J. Electroanal. C 1997, 430, 205. (b) Horr, T. J.; Arora, P. S.; Ralston, J.; Smart, R. S. Colloid Surf. A-Physicochem. Eng. Asp. 1995, 102, 181. (c) Fadley, C. S. Electron Spectroscopy; Baker, A. D., Brundle, C. R., Eds.; Academic Press: London, 1978; Vol. 2, pp 2-157. (d) Vereecke, G.; Rouxhet, P. G. Surf. Interface Anal. 1999, 27, 761
(6) Kappen, P.; Reihs, K.; Seidel, C.; Voetz, M.; Fuchs, H. Surf. Sci. 2000, $465,40$.

(7) Manson, S. T.; Dill, D. Electron Spectroscopy; Baker, A. D., Brundle, C. R., Eds.; Academic Press: London, 1978; Vol. 2, pp 157197.

(8) Caution: Alkylsilanes are reactive toward $\mathrm{O}_{2}$ and $\mathrm{H}_{2} \mathrm{O}$. All manipulations must be carried out in an inert atmosphere.

(9) Lee, S.; Makan, S.; Banaszak Holl, M. M.; McFeely, F. R. J. Am. Chem. Soc. 1994, 116, 11819.

(10) Himpsel, F. J.; Jugnet, Y.; Eastman, D. E.; Donelon, J. J.; Grimm, D.; Landgren, G.; Marx, A.; Morar, J. F.; Oden, C.; Pollak, R. A.; Schneir, J.; Crider, C. A. Nucl. Instr. Methods Phys. Res. 1984, 222, 107.

(11) Photon energies used to investigate the chemical properties of the monolayers were selected so as to minimize the photoelectron escape depth and changes in the photoelectron cross section while the photon flux from the monochromator was maximized.

(12) Stobinski, L.; Dus, R. Vacuum 1994, 45, 299

(13) Initial state effects refer to structural and compositional features of the material that influence the energy level of the core state prior to interaction with the exciting photon. In general, any change that affects the valence electron distribution will also cause the energy of the core electrons to vary.

(14) Final state effects refer to mechanisms that serve to stabilize (or destabilize) the positively charged core-hole state that is formed upon ejection of the photoelectron from the emitting atom.

(15) (a) Landemark, E.; Karlsson, C. J.; Chao, Y.-C.; Uhrberg, R. I. G. Phys. Rev. Lett. 1992, 69, 1588. (b) Wertheim, G. K.; Riffe, D. M.; Rowe, J. E.; Citrin, P. H. Phys. Rev. Lett. 1991, 67, 120.

(16) Pehlke, E.; Scheffler, M. Phys. Rev. Lett. 1993, 71, 2338

(17) (a) Zhang, K. Z.; Greeley, J. N.; Banaszak Holl, M. M.; McFeely, F. R. J. Appl. Phys. 1997, 82, 2298. (b) Kaindl, G.; Chiang, T.-C.; Eastman, D. E.; Himpsel, F. J. Phys. Rev. Lett. 1980, 45, 1808.

(18) Karlsson, C. J.; Landemark, E.; Johansson, L. S. O.; Karlsson, U. O.; Uhrberg, R. I. G. Phys. Rev. B 1990, 41, 1521.

(19) Terry, J.; Linford, M. R.; Wigren, C.; Cao, R.; Pianetta, P.; Chidsey, C. E. D. J. App. Phys. 1999, 85, 213.

(20) Ratio calculated by setting the area of the hexylsilane C 1s core level equal to 6 carbons.

(21) Bain, C. D.; Whitesides, G. M. J. Phys. Chem. 1989, 93, 1670.

(22) Though not universally accepted, the second nearest neighbor $\mathrm{C}$, $\mathrm{SiCH}_{2}-\mathrm{CH}_{2}$, will also be shifted to a slightly higher binding energy and contribute to the increase in the fwhm of the $\mathrm{C} 1 \mathrm{~s}$ core level. For information regarding the effect of second nearest neighbors on chemical shifts in photoelectron spectra, see: Zhang, K. Z.; Litz, K. E.; Banaszak Holl, M. M.; McFeely, F. R. Appl. Phys. Lett. 1998, 72, 46.

(23) Pireaux, J.-J.; Caudano, R. Phys. Rev. B 1977, 15, 2242.

(24) Kanai, T.; Furukawa, S.; Maeda, Y.; Hayashi, Y.; Oka, K.; Dohmaru, T.; West, R. J. Phys.: Condens. Matter 1998, 10, 883.

(25) Briggs, D.; Seah, M. P. Practical Surface Analysis, 2nd ed.; Wiley: Chichester, U.K., 1990.

(26) Yarmoff, J. A.; Joyce, S. A.; Cartier, E.; McFeely, F. R. J. Electron Spectrosc. Relat. Phenom. 1990, 52, 221.

(27) Laibinis, P. E.; Bain, C. D.; Whitesides, G. M. J. Phys. Chem. 1991, 95, 7017.

(28) Beard, B. C.; Brizzolara, R. A. J. Vac. Sci. Technol. A 1996, 14 , 89.

(29) Lamont, C. L. A.; Wilkes, J. Langmuir 1999, 15, 2037.

(30) Shimada, H.; Matsubayashi, N.; Imamura, M.; Sato, T.; Nishijima, A. Appl. Surf. Sci. 1996, 100-101, 56.

(31) Mahan, G. D. Phys. Rev. B 1970, 2, 4334.

(32) (a) Brizzolara, R. A.; Beard, B. C. Surf. Interface Anal. 1999, 27, 716. (b) Powell, C. J.; Jablonski, A. Surf. Sci. 2001, 488, L547.

(33) As noted by Powell (Powell, C. J. J. Elect. Spec. Relat. Phenom. 1988, 47, 197), a "universal" curve that is applicable in all situations does not exist.

(34) In the course of this work, a large range of values was employed to try to fit the data. As will be seen, the curves obtained will be the same regardless so long as the values employed are different by $11 \mathrm{~A}$.

(35) (a) Lindau, I.; Spicer, W. E. J. Electron Spectrosc. Relat. Phenom 1974, 3, 409. (b) Tougaard, S.; Sigmund, P., Phys. Rev. B 1982, 25, 4452

(36) Data for the so-called "striped phase" for alkanethiols on Au should exhibit a curve with an intensity similar to the $3 \AA$ case. To our knowledge, determination of the thickness of these layers by XPS has never been performed. For more on the striped phase of alkanethiols on $\mathrm{Au}$, see: Camillone, N., III; Eisenberger, P.; Leung, T. Y. B.; Schwartz, P.; Scoles, G.; Poirier, G. E.; Tarlov, M. J. J. Chem. Phys. 1994, 101, 11031.

(37) Although the intensities of the initial Au $4 \mathrm{f}$ photoelectrons are nominally identical, the model relies on the assumption that a similar number of octylsilane and octadecylsilane molecules react with the surface to form a monolayer. 